http://jmscr.igmpublication.org/home/ ISSN (e)-2347-176x ISSN (p) 2455-0450 crossref DOI: https://dx.doi.org/10.18535/jmscr/v8i2.15

\author{
Journal Of Medical Science And Clinical Research

\title{
Various Presentations and Sites of Tuberculosis in Post Renal Transplant patients
}

\author{
Authors \\ Thakur Karan S. ${ }^{1}$, Kenwar Deepesh ${ }^{2}$, Sharma Ashish ${ }^{3}$
}

\begin{abstract}
Patients with Chronic Renal failure, with end stage kidney disease are the candidates undergoing renal transplant. Organ transplantation is followed by use of immuno-suppressants to prevent graft rejections. This lowers host immunity, which exposes the patients to various opportunistic infections. In developing countries like India where the burden of $T B$ is very high, recipients of solid organs are under high risk to acquire tuberculosis. In general population Lung is the main site of development of TB. Other sites of involvement are lymph nodes, peritoneum and pleura. Fever and cough are the main presenting symptoms. In Transplant patients TB may develop in pulmonary or extrapulmonary sites.

Thus knowledge of TB, its clinical presentations, and its sites of involvement in renal transplant patients becomes very important.

Keywords: Renal Transplant, TB-Tuberculosis, ATT- Anti tubercular Therapy.
\end{abstract}

\section{Introduction}

Renal Transplantation increases the survival in CKD patients who are on dialysis. Transplant candidates requires immunosuppresants. Use of immunosuppresants leads to attack by different opportunistic infections. In developing countries like India where TB is already a big health problem, patients with transplant are at high risk to acquire this infection.

TB can develop by reactivation, can be transmitted via donor organ or it can be acquired as an airborne infection. Reactivation of previously acquired infection is the commonest mode of developing TB in developing countries. Reinfection occurs only in few. This should especially be considered in the presence of multidrug resistant organisms. The donor graft has also been shown to be the carrier in some rare cases.

\section{Clinical features}

Lung is the main site of development of TB. Other sites of involvement are lymph nodes, peritoneum and pleura. The characteristic feature is fever of unknown origin. Cough, fever and weight loss remain the major symptoms in transplant patients. Patients may develop pulmonary, extrapulmonary or disseminated TB.

\section{Case Study}

A retrospective non-interventional observational study which was conducted in Department of Renal Transplant Surgery, PGIMER from

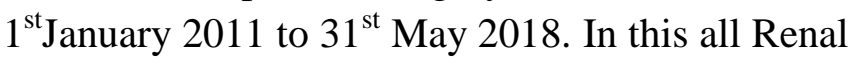
transplant patients diagnosed with TB posttransplant during that period were taken as the sample size.

During the study period 1568 patients underwent Renal Transplant. Out of these 1568 patients 68 
patients were diagnosed to have post renal transplant TB.

\section{Sources of Data}

Departmental database maintained on Microsoft Office Access supplemented by patient OPD records, indoor case files retrieved from Medical Records Department PGIMER Chandigarh and patients interviews over telephone or in person questionnaire form.

\section{Observation and Result}

In the study 1568 patients underwent Renal Transplant between 01.01.2011 to 31.05.2018. Out of these 68 patients were diagnosed with post transplant TB. In this study $4(5.9 \%)$ out 68 patients were having history of tuberculosis in past.

Most of patients presented with classical symptoms of TB. Fever and cough were the major symptoms. Other symptoms were weight loss, chest pain. In extrapulmonary TB cases like in GI TB pain abdomen loose stools were the main complaints.

Symptoms and their distribution in TB group was as-

\begin{tabular}{|l|c|}
\hline Symptom & Number (\%age) \\
\hline Fever & $47(69.1 \%)$ \\
\hline Cough & $31(45.6 \%)$ \\
\hline Weight loss & $7(10.3 \%)$ \\
\hline Chest pain & $3(4.4 \%)$ \\
\hline Others & $32(47 \%)$ \\
\hline
\end{tabular}

Majority of patients suffered from pulmonary TB $(\mathrm{n}=45,66 \%)$. Eighteen $(26.5 \%)$ patients had extrapulmonary TB including musculoskeletal, Gastrointestinal TB and genitourinary TB. Disseminated TB was diagnosed in $2(2.9 \%)$ patients.

In $3(4.4 \%)$ patients ATT was given empirically. These patients had symptoms like cough, fever but no definite diagnosis of TB/other infection could be made in sputum, $\mathrm{X}$ ray, $\mathrm{CT}$ or in any other investigations. ATT was given in suspicion of TB. All these patients responded well to ATT. Symptoms got improved.

\begin{tabular}{|l|c|}
\hline Distribution & NUMBER(\%age) \\
\hline DISSEMINATED TB & $2(2.9 \%)$ \\
\hline EMPIRICAL ATT & $3(4.4 \%)$ \\
\hline & \\
\hline Pulmonary & $45(66.2 \%)$ \\
\hline Extra-pulmonary & $18(26.5 \%)$ \\
\hline Total & $68(100 \%)$ \\
\hline & \\
\hline Extra-pulmonary TB- & $18(26.5 \%)$ \\
\hline Gastrointestinal TB & $6(8.8 \%)$ \\
\hline Genitourinary TB & $1(1.5 \%)$ \\
\hline Musculoskeletal & $5(7.4 \%)$ \\
\hline others & $6(8.8 \%)$ \\
\hline
\end{tabular}

\section{Discussion}

From the above study it is clear that Renal transplant patients are at high risk of developing clinically significant TB. The requirement of usage of immunosuppressants predisposes patients to opportunistic infections. In India prevalenceof $\mathrm{TB}$ is high in general populations. So chances of acquiring TB in patients undergoing transplant are very high, as evident from the study.

Majority of patients suffer from pulmonary TB. Fever and cough remains the major symptoms post transplant in the TB patients. Other symptoms like weight loss, chest pain and breathlessness may be there. In extrapulmonary TB cases, as in GI TB pain abdomen, loose stools can be the main complaints

TB increases both morbidity and mortality in patient undergoing transplantation. It also interferes with overall transplant acceptance.

So it becomes very necessary to study TB in renal transplant patients in our country.

\section{References}

1. Drobniewski FA, Ferguson J. Tuberculosis in renal transplant unit. Nephrology Dialysis Transplant 1996; 11: 768-70.

2. Canet E, Dantal J, Blancho G, Hourmant M, Coupel S. Tuberculosis following kidney transplantation. Nephrology Dialysis Transplantion 2011; 26: 3773-78.

3. Norman SW, Christopher JK ,Ronan P, Kidney Transplantation, 26th ed. Bailey and love 2008:1423-26. 
4. Higuita L, Nieto RJ, Gonzalez DS, Kohn $\mathrm{O}$, Alzate A, Echeverri $\mathrm{C}$ et al. Tuberculosis in renal transplant patients. $\mathrm{J}$ Bras Nefrol 2014;36:512-18.

5. Jasmer RM, Nahid P, Hopewell PC. Latent tuberculosis infection.New English Journal Med 2002; 347: 1860-66. 